\title{
Cogenerative Physics Reform Through CMPLE
}

\author{
Natan Samuels*, Eric Brewe*, and Laird Kramer* \\ *Department of Teaching and Learning, Department of Physics \\ Florida International University, 11200 SW $8^{T H}$ ST, Miami, FL, 33199
}

\begin{abstract}
We describe a physics teacher's successful pedagogical changes, which were based on the teacher's attempts to match the physics learning environment with her students' learning preferences. The pedagogical changes were observed during the teacher's implementation of the Cogenerative Mediation Process for Learning Environments (CMPLE). CMPLE is a formative intervention designed to help students and instructors collaborate to improve their classroom environment through a combination of cogenerative dialogues and time allotted to work towards their collective goals. The teacher's change in pedagogy resulted from her students' involvement in reforming their classroom. For this instrumental case study, we examined a veteran high school teacher's semester-long use of CMPLE in her Modeling Instruction classroom. Analysis of classroom videos and teacher interviews indicates that the teacher used CMPLE to adapt her pedagogy in complex ways, in order to balance her past experience and teaching values with her students' desires to be taught in ways seemingly counter to her then-current methods. We will trace her teaching practices and her self-described awareness of her students' prior experiences, to highlight notable changes concerning a particular cogenerative goal.
\end{abstract}

Keywords: Cogenerative, High School, Qualitative, Case Study, Modeling Instruction

PACS: 01.30.Cc, 01.40.Fk, 01.40.ek, 01.40.jh, 01.40.Ha

\section{INTRODUCTION}

Within the PER community, extensive advocacy efforts have been undertaken to develop and disseminate high quality research-based instructional materials to physics teachers [1]. The produced materials have been curricular as well as pedagogical in their focus. Yet during implementation, instructors have a tendency to alter those materials for a variety of reasons. Studies suggest that in practice, science educators draw on, adapt, and change such materials "in ways that they view as useful for their students and that are consistent with their personal pedagogical beliefs, classroom climate, and students' past experiences [2]." Such findings seem reasonable to us, especially in light of our teaching experiences while acting as physics instructors, and at some point or another having to adjust our curriculum, pedagogy, or both, for reasons similar to those described above. Related research has in fact shown several affective and academic benefits of instructors using analyzed survey results of their students' experiences and learning preferences to inform their local reform efforts [3]. However, instead of using surveys, our previous work has focused on designing an intervention that facilitates instructors in making these adaptations to their teaching for their specific and varied classroom contexts. A key feature of our intervention is a method for instructors to include students' input, active participation, and increased agency in developing, guiding, and implementing their reform efforts. This paper will describe some of the pedagogical changes made by a high school physics teacher while using our intervention, as well as her students' influence on those changes.

\section{CMPLE: A FRAMEWORK FOR COGENERATIVE REFORM}

The method we identified as most useful for instructors to include their students in classroom reform is a type of discussion known as "cogenerative" discussion. A cogenerative discussion (cogen) is an egalitarian discussion enacted between instructors and students in order to negotiate and produce goals for changing their teaching and learning practices [4]. Cogens have been successful for that purpose in a number of physics learning contexts [5]. Using cogens, instructors can gain understandings from their students about their learning preferences, opinions about the classroom environment, and past learning experiences. Likewise, cogens can function as an opportunity for students to understand instructors' pedagogical beliefs and intentions. Then, through negotiation, goals can be set to adjust the teaching and learning to best match these new understandings.

Our designed intervention is called the Cogenerative Mediation Process for Learning Environments (CMPLE), because cogens are the 
centerpiece of its overarching and cyclical framework [6]. CMPLE entails participants reflecting on their learning preferences, describing their learning preferences and experiences to each other, using them to develop classroom goals (via periodic cogens), and a time period of working towards their goals.

CMPLE is a "formative" intervention, and its design principles have been borrowed from the sociocultural field of Activity Theory. "Formative" interventions differ from their "linear" counterparts in that participants can 1) choose their own issues for the intervention to address, 2) negotiate the process of the intervention, and 3) generate "locally appropriate" solutions [7]. As comparison, designers of linear interventions dictate its contents and goals, and seek to control for the presumed variables prior to implementation. These labels are analogous to the observed categories of "emergent" and "prescribed" for reform change strategies in undergraduate science instruction [8]. Through the use of formative interventions, participants can develop agency. In the case of CMPLE, the agency of instructors can derive from their knowledge that their pedagogical changes are connected to their students' preferences and experiences; whereas students' agency can develop from their ability to influence how they are being taught.

\section{RESEARCH CONTEXT AND DESIGN}

This research is part of a larger instrumental case study [9], in which we are interested in how instructors' use of CMPLE facilitates their local cogenerative reform efforts. These data were collected in an honors physics course taught by a participating teacher, Dr. Lana Mendez (alias). At the time of the study (spring 2012 semester), Dr. Mendez had been teaching for 11 years at a private school, and had been using the research-based reform "Modeling Instruction in High School Physics" curriculum for the previous 2 $1 / 2$ years. She told us that she chose to participate in this study and enact CMPLE with her $5^{\text {th }}$ period honors physics class because she had been looking for meaningful ways to give her students more "voice" in her classroom. CMPLE, she felt, provided her with a step-by-step framework for her to hear what her students had to say about her class, but also adjust her teaching methods to respond to their ideas.

Our research question for this portion of the research is, "How did CMPLE influence Dr. Mendez's pedagogical shift from providing teacher-led examples to providing subtle hints?" The first author gathered over 50 hours of classroom video, via two simultaneously recording cameras, and was not directly involved in any teaching and learning activities. Periodically Dr. Mendez was interviewed concerning her views on the progress of her CMPLE implementation (more than 6 hours audio were recorded). All audio interviews and videos of the two CMPLE cogens were transcribed. The interviews and video data were then used to track implementation of, and teacher reflection on the cogenerative goals. The following narrative will briefly describe how Dr. Mendez and her students negotiated, implemented, and subsequently modified one cogenerative goal through using CMPLE over the four month time period. We will answer our research question by providing evidence that pedagogical changes occurred as a result of the teacher following the CMPLE process. In addition, we will focus on the transcribed interviews with Dr. Mendez's to inform us (and report here) why she made those changes, and some effects they had on her understanding of her students' learning and her own teaching.

\section{COGEN \#1: BUILDING NEW MODEL OF PRACTICE}

Dr. Mendez introduced CMPLE to her class when they returned from their winter break. She did so by assigning an open-ended homework reflection (as described in the CMPLE Users' Guide [10]) designed to elicit students' learning preferences. The next day of class (January $12^{\text {th }}$ ), she led a whole-class cogen in which she and her students compared their learning preferences with her then-current pedagogical practices. She began by asking students to describe their 1 or 2 most important learning preferences. A student "scribe" volunteered to help keep track of the preferences being discussed. During the cogen, several students voiced their preference to have more "one-onone" help from the teacher. Dr. Mendez responded that she would prefer to teach in a way that generally helps students as groups, rather than as individuals all the time. Through a brief round of negotiation, a goal was agreed upon for the teacher to lead (or have students lead) worksheet examples at the front board, before the students work problems on their own (or as groups). While setting this and the several other CMPLE goals, Dr. Mendez wrote them clearly on the large whiteboard at the front of the classroom.

During the research interview immediately following this cogen, Lana revealed that she was "torn" concerning this new model of practice. She was concerned that as a result of her making this change, students would start "matching what I'm doing, as opposed to figuring out how to do it on their own." However, Dr. Mendez remained optimistic enough to enact this and all of the cogenerative changes upon which she and her students had agreed. 


\section{COGEN \#2: ADJUSTING NEW MODEL OF PRACTICE}

Within a week of the first cogen, Dr. Lana Mendez, the teacher, posted the agreed-upon CMPLE goals on printed sheets of paper on a wall in her classroom. Throughout the next three months, Lana was observed implementing instruction designed to address that goal (as well as several other goals developed during the first CMPLE cogen). During that time, video recordings and researcher observations showed her leading solutions to the first problems on the worksheets she handed out in class. Sometimes she stood in front of the class and wrote on the board, while other times she sat in the back of the class and asked for student volunteers. In both cases, she implemented that change as an interactive activity; utilizing such pedagogical techniques as Socratic questioning, drawing multiple representations, and requiring active student participation. Prior to the second CMPLE cogen, she informed the researcher that she felt confident her students would be satisfied with her implementation of that goal.

On April $4^{\text {th }}$, Lana introduced the second cogen by asking students to discuss their progress (as well as her progress) in achieving their goals. Regarding the goal of "teacher-led examples", some students surprisingly expressed the opinion that Lana "could do more teacher-led examples". Students also discussed how Lana only led the "easy" problems on the board, and requested that she increase the overall number of problems she led. Lana responded by expressing her concern that the students wanted to rely on her to "make connections" to their prior knowledge, for the harder problems. Since she was not willing to increase the amount of worked-out problems, she negotiated by asking the students, "What can we do in class to help you make that connection?" One student suggested, "What helps me is if you make little hint-offs". After further discussion, Dr. Mendez agreed to give students "hints on new concepts", in order to get them "to think along the right lines."

In the research interview immediately following the second cogen, Lana referred to a similar tension in this issue, because "it defeats the purpose if I do too much." Nonetheless she was cautiously willing to change her pedagogy again, because she felt the cogen was fruitful for both her and her students' understanding of each other's positions, and the new "hints" goal was perhaps an improvement over the original goal.

\section{END OF YEAR: REFLECTING ON CMPLE}

Similar to her efforts to actualize the "teacher-led examples" goal from the first cogen, Dr. Mendez attempted to change her instruction in line with the new "hints" goal from the second cogen. In an interview shortly before the end of the semester, approximately 7 weeks after cogen \#2, Dr. Mendez was asked about her progress of working toward the "hints" goal. In response, she explained that she occasionally gave verbal hints on problems she considered to be "well designed to target the misconception", but that tend to leave students "stuck". As an example, she described a recent class discussion about a problem from the Electric Fields unit, in which a field diagram is useful for constructing a solution. She explained that due to the wording of the question however, students instead drew force diagrams. As a result, the students were having difficulty solving the problem, and none had proceeded beyond that point. Dr. Mendez saw this as an opportunity to give students a hint, rather than working through the problem on the front board. She recalled that after she suggested students think of the physical situation in terms of a field, an excited student immediately responded, "Oh, the field lines are going to cancel!" Dr. Mendez informed us that student was "not even my strongest student", and was impressed because she didn't need to draw the field representation before responding. Dr. Mendez reflected that in general, her hints helped students feel "like they came up with it on their own," instead of waiting for the her to come tell them the answer. Extending the theme of student agency in the classroom, Lana noted that, "...if [students] can feel they figured it out on their own, it's so good for their confidence."

A student corroborated Dr. Mendez's perceptions during a class discussion less than an hour after the interview quoted above. Dr. Mendez initiated the discussion to get feedback from her students about the effects of the cogenerative pedagogical changes that took place during the semester. When Dr. Mendez asked a student named "Jenny" how she was affected by the implementation of the "giving hints" goal, the student first recalled times when she felt "not confident" in her problem solving when she "couldn't get past" a certain step. Yet, she further explained that Dr. Mendez's new hints "triggered something." Jenny cited a recent example when Dr. Mendez suggested she draw a force diagram for a particular problem. As a result, Jenny explained that she thought to herself at the time, "Oh, ok. I can do that!" During this end-ofyear discussion, her newfound self-efficacy (confidence in her ability to solve physics problems 
[11]) was more important to Dr. Mendez than whether that particular problem was solved correctly.

\section{DISCUSSION}

The students' original preference to have more oneon-one attention from the teacher resulted in pedagogical changes of teacher-led examples (of varying difficulty), and then to the teacher giving hints. Those pedagogical changes were the teacher's attempts to address her students' preferences, prior experiences, and most importantly, their learning of physics. Throughout her time implementing CMPLE, Dr. Mendez continuously made efforts to listen and respond (verbally and through pedagogical changes) to her students' positive and negative criticisms of her course. We are aware that some of Dr. Mendez's changes described in this paper may not be considered aligned with commonly accepted physics reform teaching practices. However, we take the position that because some amount of local recontextualization of reform practices by teachers is to a degree inevitable [2], the reasons for those changes should be explicitly relevant to the classroom participants. We remain impressed with this teacher's ability to balance the goals and content of the Modeling Instruction curriculum with her students' (and her own) sometimes conflicting, but always evolving conceptions and experiences of teaching and learning physics.

With regards to the CMPLE's influence on Lana's pedagogical changes, we have verified that changes were made. Those changes (described throughout this paper) were introduced and/or adapted after each CMPLE cogenerative discussion. In the time between the cogens Dr. Mendez worked to actualize the agreedupon changes. In an Activity Theory sense, her holistic change process is reminiscent of Engeström's "expansive cycle of learning", in which activities shift from abstract questioning to making actual changes in the real world [7].

Ultimately, instructors are responsible for implementing and facilitating changes to their classroom, no matter how cogenerative in nature those changes are. Dr. Mendez explained that although she was previously interested in including students' opinions into her course structure, she knew of "no formal way of addressing the class and saying let's look at [your] preferences." She would have had to rely on students to take the initiative to tell her they would like to try something new, but "that almost never happens." CMPLE provided her with a framework for eliciting and pedagogically responding to those suggestions. The combination using the CMPLE framework to work towards and experience cogenerative reform gave Dr. Mendez a deeper understanding of her students' teaching and learning perceptions, while giving students the opportunity to affect how they were taught.

For future research, a more complete analysis of CMPLE in Dr. Mendez's classroom is being prepared for publication. For our implementation work we are considering CMPLE for use with in-service physics teacher professional development. Specifically we are investigating and developing ways that CMPLE could be built into in-service professional development programs as a formative teaching assessment.

\section{ACKNOWLEDGMENTS}

Dr. Lana Mendez and her students, Renee Michelle Goertzen, Kimberley Barnes, the 2013 FFPER Graduate Symposium participants, the FIU PER Group, the reviewers and editors of the 2013 PERC Proceedings, and NSF Award \# 0802184.

\section{REFERENCES}

1. Cummings, K. (2011). A developmental history of physics education research. In Second Committee Meeting on the Status, Contributions, and Future Directions of Discipline-Based Education Research.

2. Barab, S. A., \& Luehmann, A. L. (2003). Building sustainable science curriculum: Acknowledging and accommodating local adaptation. Science Education, 87(4), 454-467.

3. Fraser, B. J., \& Wubbels, T. (1995). Classroom learning environments. In B. Fraser, H. J.Wallberg (Eds.), Improving science education (pp. 140-141). Chicago, IL: National Society for the Study of Education.

4. Tobin, K. (2008). Fostering science learning in diverse urban settings. In C. Henderson, M. Sabella, L. Hsu (Eds.) Proceedings from the 2008 Physics Education Research Conference, AIP Conference Proceedings 1064 (pp. 50-52). New York: American Institute of Physics.

5. Stith, I., Roth, W-M. (2008) Students in action: Cogenerative dialogues from secondary to elementary schools. Rotterdam: Sense Publications.

6. Samuels, N., Brewe, E., \& Kramer, L. (2013, January). Instructional changes based on cogenerative physics reform. In PERC Proceedings (Vol. 1513, p. 38).

7. Engeström, Y. (2011). Activity theory and learning at work. The SAGE hndbk. of workplace learning, 86-104.

8. Henderson, C., Beach, A. L., \& Finkelstein, N. (2012). Four categories of change strategies for transforming undergraduate instruction. Transitions and Transformations in Learning and Education, 223-245.

9. Stake, R. E. (1995). The art of case study research. Sage Publications.

10. Samuels, N. (2012). CMPLE Users' Guide. Available online at http://fiuperg.pbworks.com/w/page/37761362/ Supplemental-Research-Material

11. Sawtelle, V., Brewe, E., \& Kramer, L. H. (2012). Exploring the relationship between self-efficacy and retention in introductory physics. JRST 49(9), 1096-1121. 